www.jmscr.igmpublication.org

Impact Factor 5.84

Index Copernicus Value: 83.27

ISSN (e)-2347-176x ISSN (p) 2455-0450

crossref DOI: _https://dx.doi.org/10.18535/jmscr/v5i7.83

Journal Of Medical Science And Clinical Research

IGM Publication

An official Publication of IGM Publication

\title{
Single Puncture CT Guided fine-needle aspiration cytology (FNAC) and Tru-cut biopsy in Indeterminate Lung Lesions
}

\author{
Authors \\ Dr Richa Verma ${ }^{1}$, Dr Shikha Sood ${ }^{2}$, Dr Sanjiv Sharma ${ }^{3}$, Dr Navneet Sharma ${ }^{4}$, \\ Dr Sudarshan Kumar Sharma , Dr Malay Sarkar ${ }^{6}$ \\ ${ }^{1,4}$ Senior Resident, Department of Radiodiagnosis, \\ ${ }^{2}$ Assistant Professor, Department of Radiodiagnosis \\ ${ }^{3}$ Professor, Department of Radiodiagnosis \\ ${ }^{5}$ Professor, Department of Pathology \\ ${ }^{6}$ Professor, Department of Pulmonary Medicine
}
Abstract
Purpose
1. To establish cytological and histopathological diagnosis of indeterminate focal and diffuse lung lesions
2. Comparison of coaxial lung FNAC and trucut biopsy
3. Combined complications of coaxial lung FNAC and trucut biopsy
4. Establishment of guidelines to use FNAC or Tru-cut biopsy or both in different indeterminate lung lesions

Materials and Methods: Single puncture co-axial FNAC and biopsy was done in 76 patients referred to the department of radiodiagnosis, Indira Gandhi Medical College, Shimla who had indeterminate lung lesions on contrast enhanced CT. Role of co-axial biopsy needle in diagnosing indeterminate lesion was explored and comparison of both the techniques along with their complications was done using appropriate statistical tests.

Results: Overall sensitivity of biopsy (81.08\%) was higher than FNAC (74.29\%) but its specificity was low (50\% versus $83.3 \%$ ). Sensitivity of biopsy for benign lesion was higher than FNAC (83.3\% versus $76.6 \%$ ) but was comparable for malignant lesions (76.92\% versus 76.6\%). Hence FNAC and biopsy are complementary to each other than done alone (sensitivity 94.59\%, specificity 97.22\%).

Conclusion: Both the CT guided coaxial FNAC and trucut biopsy are complementary and should be done in a single sitting for a better diagnostic yield. Use of coaxial needle is more convenient for the patients rather than single biopsy needle.

\section{INTRODUCTION}

Computerized tomography (CT) guided fine needle aspiration cytology (FNAC) of lung lesions has rapidly emerged as a less-invasive, cheap, rapid and fairly accurate diagnostic tool for providing prompt classification of tumors. It has a diagnostic accuracy rate of $94 \%$ and a sensitivity rate of $95 \%^{(1)}$, however, its diagnostic sensitivity rate in benign lung diseases is reported to be $12 \%^{(2)}$ to $23.5 \%{ }^{(3)}$ only.

CT-guided Percutaneous Transthoracic Biopsy (PTB) is another diagnostic invasive modality 
which can be performed by either single needle trucut biopsy or by coaxial needle biopsy. Both techniques produce an overall diagnostic accuracy $98 \%$ for malignant lesions. The major advantage of coaxial technique is that a single pleural puncture is made, which allows multiple biopsies to be taken while a single needle biopsy technique causes two or more pleural punctures per procedure ${ }^{(4)}$ hence causes inconvenience to the patient with increased risk of complications. In comparison with FNAC, core needle biopsy (CNB) achieves $90 \%$ specificity for benign lung lesions and sensitivity of $92 \%$ for malignant lung tumour with overall diagnostic accuracy of $91 \%$, positive predictive value of $97 \%$ and and negative predictive value of $75 \%{ }^{(5)}$, with a risk of pneumothorax ranging from 17 to $26.6 \%{ }^{(6)}$ and pulmonary haemorrhage ranging from $4-27 \%^{(7)}$

The advantage of CNB includes the preservation of tissue architecture of the specimen, which is important in the assessment and sub-typing of some tumours and helps in applying immunohistochemical techniques ${ }^{(8)}$. The tissues obtained via core biopsy allow better characterization of different cell types and is especially useful in lympho-proliferative disorders $^{(7)}$. CT-guided $\mathrm{CNB}$ is a feasible technique in acquisition of cancer tissues for EGFR gene mutation analysis. The use of CTguided aspiration and core biopsy in a single sitting resulted in a high diagnostic yield for pulmonary nodules smaller than $1 \mathrm{~cm}$. The use of the aspiration method alone is an independent risk factor associated with diagnostic failure $^{(9)}$ while combined use of FNAC and CNB yields better results with diagnostic accuracy of $75 \%$ for benign lesions ${ }^{(10)}$. The complication rates of FNAC with the addition of a biopsy are similar to those reported in the literature for FNAC alone, hence sequential FNA and CNB improve the diagnostic yield of percutaneous CT-guided procedures in malignant lesions, especially in cases of uncertain diagnosis, without an increase in complication rate. In cases highly suggestive of a benign lesion, $\mathrm{CNB}$ alone may be considered as its yield is similar to that of same-session sequential CT-guided FNA and CNB procedure $^{(11)}$.

The aim of present study is to establish and compare the cytological and histopathological diagnosis and complications of focal and diffuse indeterminate lung lesions by use of both FNAC as well as a biopsy, in a single sitting with a single puncture, thus setting the guidelines for the use of appropriate technique in future.

\section{MATERIALS AND METHODS}

In this prospective study, 76 patients from July 2014 to June 2015 underwent CT guided coaxial FNAC and trucut biopsy for indeterminate lung lesions. All patients were followed up for complications and results.

\section{Study technique-}

Non-contrast CT thorax was performed at $10 \mathrm{~mm}$ section interval $[0.625 \mathrm{~mm}$ slice thickness, 3.3 to $5 \mathrm{~s}$ scanning time] with a window level of-475 Hounsfield Units(HU) and window width of 1900HU using the 64-slice CT scanner (Model: VCT Xte; GE Healthcare).Patient positioning was chosen based on the location and size of the lesion as depicted on previous CT thorax. Needle path were chosen to avoid pulmonary veins, arteries, bullae and fissures. Prone position was preferred wherever possible. Supine position was used if the lesion was located anteriorly. Oblique and decubitus positions were reserved if prone and supine accessibility of lesion was not possible. A limited CT of the lesion as depicted on previous CT thorax was performed to confirm the location, size, depth, necrosis and the safe access for needle track. By choosing the appropriate CT slice location and with the help of laser light a horizontal line was marked with a marker on the skin of the patient. A grid of metallic pins was placed on this marked horizontal line and limited CT sections were again taken. The most appropriate site and depth of needle entry was chosen and a perpendicular vertical line parallel to the gantry was drawn to first marked horizontal line on the skin. The point 
of intersection of these two lines was the site of entry. The skin around the insertion site was cleaned with povidone iodine and spirit, and a sterile drape was placed. The skin, subcutaneous tissue and trajectory along the path of needle including the intercostals muscles and nerves along the ribs were anesthetised with the direct injection of $5 \mathrm{ml}$ of $2 \%$ lignocaine. Five $\mathrm{ml}$ of this anaesthetic agent was given in the same needle path radially while withdrawing to check for entry into venous system and in the end the skin around the entry site was infiltrated with lignocaine to raise a bleb.

Coaxial biopsy needle (US Biopsy, Coaxial SABD Biopsy System) of following types was used according to the size and depth of lesion:

$18 \mathrm{Gauze} X 9 \mathrm{~cm}$ (Introducer $17 \mathrm{~g}(1.6 \mathrm{~mm}) \times \mathrm{cm}(3.9 \mathrm{c}$

$\mathrm{m}), \operatorname{SABD}-18 \mathrm{~g}(1.2 \mathrm{~mm}) \times 9 \mathrm{~cm},(15 \mathrm{~mm}, 20 \mathrm{~mm}))$

18 Gauze $\mathrm{X} \quad 15 \mathrm{~cm}$ (Introducer-

$17 \mathrm{~g}(1.6 \mathrm{~mm}) \times 13 \mathrm{~cm}(10 \mathrm{~cm})$, SABD-

$18 \mathrm{~g}(1.2 \mathrm{~mm}) \times 15 \mathrm{~cm},(15 \mathrm{~mm}, 20 \mathrm{~mm}))$

FNAC needle of $22 \mathrm{G}$ with length of $9 \mathrm{~cm}$ or 15 $\mathrm{cm}$ was used depending on the depth of the lesion.

Puncture needle/introducer with its sheath was introduced into the lesion. New axial slices were made to confirm the correct location of the needle. The puncture needle was taken out and the sheath was left in situ. FNAC needle was introduced through the sheath into the target area of the lesion. If repositioning is necessary, the needle was adjusted without exiting the lung .Teasing of tissue was done and negative pressure was applied with piston of the $20 \mathrm{cc}$ syringe and aspirated sample was transferred to glass slides to make smears. Then the FNAC needle was removed and puncture needle was again introduced to avoid air entry while the loaded gun was being introduced. The puncture needle was again taken out without disturbing the sheeth. Loaded biopsy gun was introduced through the sheath with notch adjusted at $1.5 \mathrm{~cm} \mathrm{~cm}$ (for lesions $<1 \mathrm{~cm}$ ) or $2.0 \mathrm{~cm}$ (for lesions $>1 \mathrm{~cm}$ ). The gun was fired and vaccum was created and then the gun was taken out. The puncture needle again inserted into the sheath to avoid air entry. Required shots were taken by slightly changing the direction of the biopsy gun depending on the material obtained.

\section{RESULTS}

A total of 76 patients of indeterminate lung lesions between the age group of 18 to 80 years (mean age of $62.3 \pm 11.5$ years) were included in the study. CT guided FNAC followed by biopsy were done in all the patients in a single setting.

In our study, the results of FNAC, biopsy, combined FNAC and biopsy were calculated in terms of sensitivity, specificity, positive predictive value, negative predictive value, positive likelihood ratio and negative likelihood ratio. Benign and malignant results were taken as positive cases, and indeterminate results were negative cases. These results were compared with the clinical diagnosis which was taken as gold standard.

Clinically total number of malignant lesions were $53(69.7 \%)$ and benign lesions were 23(30.2\%). FNAC was done in all 76 patients. There were 11 $(14.5 \%)$ benign lesions, 42(55.2\%) malignant lesions, and $23(30.2 \%)$ indeterminate lesions due to inadequacy of sample obtained. The sensitivity, specificity, positive predictive value, negative predictive value and diagnostic accuracy of of FNAC were $74.29 \%, 83.33 \%, 98.11 \%$, $21.74 \%$ and $75 \%$ respectively. These results are shown in table I. The sensitivity, specificity for the detection of malignant lesions is $76.6 \%$ and $100 \%$ respectively (table II), and that of benign lesions is $47.62 \%$ and $92.31 \%$ respectively (table III).

Biopsy showed 20(26.3\%) cases having benign lesions and 40(52.7\%) as malignant lesions. In 16 patients $(21.0 \%)$ biopsy yielded indeterminate results due to insufficient samples. The sensitivity, specificity, positive predictive value, negative predictive value, diagnostic accuracy of biopsy were $81.08 \%, 50 \%, 98.36 \%, 6.67 \%, 80.2 \%$ respectively (Table I).The sensitivity and specificity for 
malignant lesions were $76.92 \%$ and $100 \%$ (Table-II), and for benign lesions were $83.33 \%$ and $100 \%$ respectively(Table-III).

The overall sensitivity, positive predictive value, diagnostic accuracy of both FNAC and biopsy were $90.38 \%, 100 \%$ and $92 \%$ respectively
(Table-I). The sensitivity and specificity for malignant lesions were $90.38 \%$ and $100 \%$ respectively (Table-II) and for benign lesions were $90 \%$ and $60 \%$ respectively (Table-III).

Table I-Performance in all lesions

\begin{tabular}{|lccc|}
\hline & FNAC & Biopsy & FNAC+Biopsy \\
Sensitivity & $74.29 \%$ & $81.08 \%$ & $94.59 \%$ \\
Specificity & $83.3 \%$ & $50 \%$ & - \\
Positive Likelihood Ratio & 4.46 & 1.62 & 0.95 \\
Negative Likelihood Ratio & 0.31 & 0.38 & - \\
Positive Predictive Value & $98.11 \%$ & 98.36 & $97.22 \%$ \\
Negative Predictive Value & $43.48 \%$ & 6.67 & $0 \%$ \\
\hline
\end{tabular}

Table II-Performance in malignant lesions

\begin{tabular}{|lccc|}
\hline & FNAC & Biopsy & FNAC+Biopsy \\
Sensitivity & $76.36 \%$ & $76.92 \%$ & $90.38 \%$ \\
Specificity & $100 \%$ & $100 \%$ & $100 \%$ \\
Positive Likelihood Ratio & - & - & - \\
Negative Likelihood Ratio & 0.24 & 0.23 & 0.10 \\
Positive Predictive Value & $100 \%$ & $100 \%$ & $100 \%$ \\
Negative Predictive Value & $43.48 \%$ & $25 \%$ & $16.67 \%$ \\
\hline
\end{tabular}

Table III-Performance in benign lesions

\begin{tabular}{|lccc|}
\hline & FNAC & Biopsy & FNAC+Biopsy \\
Sensitivity & $47.62 \%$ & $83.33 \%$ & $95 \%$ \\
Specificity & $92.31 \%$ & $100 \%$ & $60 \%$ \\
Positive Likelihood Ratio & 6.19 & - & 2.37 \\
Negative Likelihood Ratio & 0.57 & 0.17 & 0.08 \\
Positive Predictive Value & $90.91 \%$ & $100 \%$ & $90.48 \%$ \\
Negative Predictive Value & $52.17 \%$ & $75 \%$ & $75 \%$ \\
\hline
\end{tabular}

Among malignancies, maximum number of cases were of adenocarcinoma and among benign lesions tuberculosis was the commonest (Table IV).

Table IV-Distribution of Lesions

\begin{tabular}{|l|c|c|}
\hline MALIGNANT LESIONS & FNAC & BIOPSY \\
\hline Adenocarcinoma & 12 & 14 \\
\hline Squamouscell carcinoma & 8 & 10 \\
\hline Small cell carcinoma & 8 & 5 \\
\hline Non small cell carcinoma & 9 & 2 \\
\hline Bronchoalveolarcarcinoma & 0 & 2 \\
\hline Unclassified carcinoma & 4 & 3 \\
\hline Metastases & 2 & 2 \\
\hline Lymphoma & 0 & 1 \\
\hline BENIGN-LESIONS & & \\
\hline & FNAC & Biopsy \\
\hline Pulmonary TB & 2 & 3 \\
\hline Thymoma & 0 & 2 \\
\hline Hamartoma & 1 & 1 \\
\hline Purulent infection & 1 & 0 \\
\hline
\end{tabular}

Out of 76 patients, 18 patients (23.7\%)developed pneumothorax (Table V). Out of these patients only $2(11.1 \%)$ patients required chest tube insertion. 
Table V-Pneumothorax

\begin{tabular}{|lcc|}
\hline Pneumothorax & Frequency & $\%$ \\
Present & 58 & 23.7 \\
Absent & 18 & 76.3 \\
\hline
\end{tabular}

Only 9 patients $(11.8 \%)$ developed haemorrahage along tract (Table VI).. Only one patient developed mild haemoptysis(1.3\%).

Table VI- Haemorrhage along tract

\begin{tabular}{|lcc|}
\hline $\begin{array}{l}\text { Haemorrhage } \\
\text { along tract }\end{array}$ & Frequency & $\%$ \\
Present & 9 & 11.8 \\
Absent & 67 & 88.2 \\
\hline
\end{tabular}

\section{DISCUSSION}

CT guided transthoracic needle biopsy has emerged as one of the leading procedures for the diagnosis of indeterminate pulmonary and mediastinal lesions. When successful, this method may obviate the need for more invasive diagnostic approaches such as thoracoscopy, mediastinoscopy or thoracotomy. Fine-needle aspiration (FNA) provides a sample that is usually adequate for cytological and microbiological examinations, but not for a histological evaluation. The larger volume of tissue obtained by percutaneous coreneedle biopsy (CNB) enables histopathological diagnosis and more sophisticated laboratory analysis. The optimal technique for the diagnosis of intrathoracic lesions has not yet been recommended ${ }^{(11,12)}$. FNA or CNB are commonly used, while single puncture FNAC with trucut biopsy is not yet the trend.

Only a few studies are available in the literature in which both CT guided FNAC and biopsy were performed sequentially with a single puncture using coaxial approach.

Our study is in concordance with Aviram et al ${ }^{(11)}$ who showed that using sequential FNA and CNB improves specimens adequacy (95\%) and hence the rate of precise diagnosis $(94.5 \%)$. However, in their study the patient was subjected to two punctures, one for FNAC and the next for coaxial biopsy as opposed to our approach of giving single puncture to the patient for both
FNAC and biopsy. There was also presence of onsite cytologist in their study but not in ours.

Our results were also in agreement with Yamagami et $a l^{(13)}$ who performed both CT guided FNAC and biopsy under CT Fluoroscopy and the combined results $(94.2 \%)$ were better than either performed alone $(79.7 \%$ for FNAC and $89.1 \%$ for biopsy).CT guided fluoroscopy is a real time procedure, however it is not available in many centres and is associated with high radiation exposure.

Schoellnast et $a l .^{(3)}$ concluded that CT-guided biopsy of a lesion of the lung with FNA, and without an on-site cytopathologist, did not yield higher sensitivity or specificity compared to CNB alone. The result of this study was opposite to our study, which showed definite improvement in results by combining FNAC and biopsy. Our study emphasised the use of coaxial needle for performing the CT guided FNAC and biopsy of indeterminate lung lesions.

In a study performed by $\mathrm{Wu}$ et al. ${ }^{(4)}$ on the use of single or coaxial biopsy needles the results showed that both techniques yielded an overall diagnostic accuracy of $98 \%$ for malignant lesions with similar sensitivity (single needle: $96.9 \%$ vs. coaxial: $96.4 \%$ ) and specificity (single needle: $100 \%$ vs. coaxial: $100 \%)$. The major disadvantage of performing single needle transthoracic biopsy is that the correct needle positioning has to be made each time a pleural puncture is performed, hence 
more time consuming. In comparison, the coaxial system would allow multiple numbers of tissue extractions with single pleural puncture, which is more convenient, relatively easy and gives less radiation dose to the patient as sheath position is to be checked only once by CT. However, the coaxial system may be more costly approximately $21 \%$ higher than that of single needle technique per procedure. Secondly, results showed that using single needle technique does not take longer duration, in fact shorter than that of the coaxial technique when performing cutting needle biopsy. These suggest that a single needle technique may have value when considering which of techniques to use to perform transthoracic biopsies. The disadvantage of the single needle technique is that each time the needle is introduced into the lesion; image guidance is required, resulting in increased procedure time. Moreover, intervening structures are traversed each time, resulting in increased risk of complications. While a coaxial technique offers many advantages, larger caliber guiding needles are required to puncture the pleura. In the presence of a prominent internal airbronchogram or open-bronchus sign in the lesion, a coaxial technique should be used more carefully as there is an increased risk of air embolism.

\section{CONCLUSION}

In our study 76 patients had undergone $\mathrm{CT}$ guided coaxial FNAC and trucut biopsy in a single sitting. The sensitivity and diagnostic accuracy of biopsy were better than FNAC for both benign as well as malignant lesions. The sensitivity, positive predictive value and diagnostic accuracy of combined FNAC and biopsy were much higher than either FNAC or biopsy alone. The coaxial needle was also more compliant for the patients.

Thus, the inference of our study is that both the CT guided coaxial FNAC and trucut biopsy of indeterminate lung lesions should be done for a better diagnostic yield, thus both modalities are complementary to each other and the use of coaxial needle is more convenient for the patients rather than single biopsy needle.

\section{REFERENCES}

1. Swischuk JL, Castaneda F, Patel JC, Li R, Fraser KW, Brady TM, Bertino RE. Percutaneous transthoracic needle biopsy of the lung: review of 612 lesions. J Vasc Interv Radiol. 1998 Mar-Apr; 9(2):347-52.

2. Haaga JR, Alfidi RJ. Precise biopsy localization by computer tomography. Radiology. 1976 Mar; 118(3):603-7.

3. Lourenço R, Camacho R, Barata MJ, Canário D, Gaspar A, Cyrne C. CT-guided percutaneous transthoracic biopsy in the evaluation of undetermined pulmonary lesions. Rev Port Pneumol. 2006 Sep-Oct; 12(5):503-24.

4. Wu RH, Tzeng WS, Lee WJ, Chang SC, Chen $\mathrm{CH}$, Fung JL et al.. CT-guided transthoracic cutting needle biopsy of intrathoracic lesions: comparison between coaxial and single needle technique. Eur $\mathbf{J}$ Radiol. 2012 May; 81(5):e712-6.

5. Kim TJ, Lee JH, Lee CT, Jheon SH, Sung SW, Chung JH, Lee KW. Diagnostic accuracy of CT-guided core biopsy of ground-glass opacity pulmonary lesions.AJR Am J Roentgenol. 2008 Jan; 190(1):234-9.

6. Montaudon M, Latrabe V, Pariente A, Corneloup O, Begueret H, Laurent F. Factors influencing accuracy of CT-guided percutaneous biopsies of pulmonary lesions. Eur Radiol. 2004 Jul; 14(7):1234-40.

7. Winokur RS, Pua BB, Sullivan BW, Madoff DC. Percutaneous lung biopsy: technique, efficacy, and complications. Semin Intervent Radiol. 2013 Jun; 30(2):121-7.

8. Schoellnast $\mathrm{H}$, Komatz $\mathrm{G}$, Bisail $\mathrm{H}$, Talakic E, Fauster M, Ehammer $\mathrm{T}$ et al. CT-guided biopsy of lesions of the lung, liver, pancreas or of enlarged lymph nodes: value of additional fine needle aspiration (FNA) to core needle biopsy (CNB) in an offsite pathologist setting. Acad Radiol. 2010 Oct; 17(10):1275-81. 
9. Choi SH, Chae EJ, Kim JE, Kim EY, Oh SY, Hwang HJ et al. Percutaneous CTguided aspiration and core biopsy of pulmonary nodules smaller than $1 \mathrm{~cm}$ : analysis of outcomes of 305 procedures from a tertiary referral center. AJR Am J Roentgenol. 2013 Nov; 201(5):964-70.

10. Boiselle PM, Shepard JA, Mark EJ, Szyfelbein WM, Fan CM, Slanetz PJ et al. Routine addition of an automated biopsy device to fine-needle aspiration of the lung: a prospective assessment. AJR Am J Roentgenol. 1997 Sep; 169(3):661-6.

11. Aviram G, Greif J, Man A, Schwarz Y, Marmor S, Graif $M$ et al. Diagnosis of intrathoracic lesions: are sequential fineneedle aspiration (FNA) and core needle biopsy (CNB) combined better than either investigation alone? Clin Radiol. 2007 Mar; 62(3):221-6.

12. Manhire A, Charig M, Clelland C, Gleeson F, Miller R, Moss $\mathrm{H}$ et al. Guidelines for radiologically guided lung biopsy. Thorax. 2003 Nov; 58(11):920-36.

13. Yamagami T, Iida S, Kato T, Tanaka O, Nishimura T. Combining fine-needle aspiration and core biopsy under CT fluoroscopy guidance: a better way to treat patients with lung nodules? AJR Am J Roentgenol. 2003 Mar; 180(3):811-5. 